\title{
EVASÃO E PERMANÊNCIA NO PROJETO ESPORTE CIDADÃO
}

Recebido em: 23/10/2010

Aceito em: 21/03/2011

André da Silva Mello

Universidade Federal do Espírito Santo

Vitória - ES - Brasil

Sebastião Josué Votre

Universidade Gama Filho

Rio de Janeiro - RJ - Brasil

Hugo Rodolfo Lovisolo

Universidade Estadual do Rio de Janeiro

Rio de Janeiro - RJ - Brasil

RESUMO: O objetivo deste artigo é descrever e interpretar a avaliação oferecida pelos evadidos e perseverantes no Projeto de Lazer Esporte Cidadão em Vila Velha, ES. Trata-se de um estudo de caráter descritivo-interpretativo, com dados coletados por meio de entrevistas semiestruturadas. As respostas provêm de 83 adolescentes, meninos e meninas: 69 se evadiram do projeto enquanto 14 deles são remanescentes nas atividades. Foram avaliadas as reações em termos de "lealdade", "voz" e "saída". A análise crítica do discurso dos informantes revelou que o projeto não conseguiu atender às "motivações e emoções de seus membros", com espaço insuficiente para os desafios da competição. A conclusão é que os coordenadores de projetos sociais devem avaliar as emoções e perspectivas da comunidade em que intervêm e precisam oferecer atividades desafiadoras, que atendam às motivações dos participantes.

PALAVRAS-CHAVE: Atividades de Lazer. Educação Física e treinamento. Esportes.

\section{EVADING IN REMAINING IN “ESPORTE CIDADÃO” PROJECT}

ABSTRACT: This study aims at describing and interpreting the evaluation offered by members of the Esporte Cidadão Social Project, anchored in sports and physical activities and developed in a low-income urban community in the Southeast of Brazil. The answers were obtained from 83 adolescents, boys and girls, 69 from whom left the project, while 14 are still engaged on such activities. We evaluated voice power and engagement of these two groups as well as the effect of their reaction to the inadequacy of the project, leading them to give up sports and physical activities. Critical Discourse 
Analysis of the answers revealed that the social project failed to achieve its member's aims, since there wasn't enough space for competition and other kinds of challenge. This main conclusion is that social projects coordinators must evaluate the interests and perspectives of the community they intend to intervene in and, above all, must offer challenging activities, able to meet participants' goals.

KEYWORDS: Leisure Activities. Physical Education and Training. Sports.

\section{Introdução}

O Projeto de Lazer Esporte Cidadão (PEC) foi implementado a partir de um convênio entre a Secretaria Municipal de Educação de Vila Velha/ES e um curso de Educação Física do município. Esse projeto de lazer, vinculado às atividades físicas e esportivas, foi desenvolvido em uma escola pública de Soteco, bairro periférico de Vila Velha que apresenta altos índices de violência e de evasão escolar entre os jovens. $\mathrm{O}$ projeto atende a cerca de 400 adolescentes e jovens dessa comunidade (número médio de atendimento entre os anos de 2001 e 2009).

O PEC tem orientação socioeducativa, por opção explícita de seus mentores e coordenadores. A proposta pedagógica do PEC foi concebida para formar cidadãos críticos, participativos e autônomos, visando ao processo de emancipação social. Nesse sentido, os objetivos estavam relacionados com o contexto social mais amplo, tornandose instrumento de análise crítica da realidade, contribuindo para o desenvolvimento pessoal e social dos participantes. De acordo com as orientações pedagógicas do projeto, o esporte era abordado na perspectiva da inclusão social, em que valores, como seletividade e exclusão, visando à performance, são substituídos por participação e solidariedade. A tendência socioeducativa em questão era a crítico-superadora (SOARES et al., 1992) que, pautada no materialismo histórico e dialético, propõe desenvolver a leitura crítica da realidade social, via atividades físicas e esportivas, a fim de contribuir para o processo de emancipação social das classes populares. 
Neste artigo analisamos o teste da proposta, com resultados parciais favoráveis e com localização de pontos críticos que se mostraram frágeis e merecem reformulação. Entre esses pontos, avultam: pouca disponibilidade dos participantes para reflexão crítica dos conteúdos; o fato de os participantes considerarem perda de tempo utilizar parte da aula para discussões; a existência de relações assimétricas de poder entre agentes e participantes, que se manifestou via linguagem; e a incompatibilidade da proposta com as expectativas dos alunos em relação à competição esportiva, uma vez que não nega a competição esportiva, mas tampouco favorece a progressão na carreira esportiva.

Apesar de o PEC não excluir explicitamente o plano da "busca da excitação", para usar a expressão de Elias e Dunning (1992), ou da emoção e do gosto (LOVISOLO, 1995, 2001, 2002), não centra as atividades na procura de tais estados anímicos. Em outros termos, a diversão ou o entretenimento excitante não são objetivos privilegiados da intervenção, apesar de serem entendidos como dimensões naturais da atividade esportiva e física.

A partir de dados quali-quantitativos, coletados de forma aleatória, analisamos o grau de evasão e permanência de jovens no PEC e elaboramos uma interpretação das razões apresentadas pelos evadidos para se afastarem do projeto e também dos perseverantes para permanecerem nele.

Para analisarmos o grau de insatisfação dos evadidos em face à proposta adotada pelo projeto, utilizamos os conceitos de saída e voz, nos termos em que foram formulados por Hirschman (1973, p. 16-17):

Alguns membros deixam a organização: é a opção de saída. [...] os membros da organização expressam sua insatisfação diretamente à direção, a uma autoridade à qual a direção esteja subordinada, ou através de protestos gerais, dirigidos a quem estiver interessado em ouvi-los: é a opção de voz. 
Desse autor também utilizamos o conceito de lealdade dos participantes perseverantes, associado às alternativas que oferecem para superar as falhas do projeto em que se encontram:

Então, como regra, a lealdade põe de lado a saída e ativa a voz. É verdade que, frente ao descontentamento com o estado da organização, um membro pode continuar fiel mesmo que, pessoalmente, não seja influenciado, contando que alguém vai agir ou que alguma coisa vai acontecer para melhorar a situação (HIRSCHMAN, 1973, p. 83).

Enquanto a análise das vozes fornece subsídios para ações de reorientação do projeto, com vistas a aumentar a adesão, favorecer a perseverança e assim cumprir as suas finalidades, a da saída permite constatar a insatisfação dos indivíduos com as instituições, embora se deva ler com reserva as explicações dadas pelos egressos para se voltarem para outras atividades ou para outras motivações fora do PEC. O fato de os jovens dizerem que saíram porque estavam enjoados da repetição e monotonia das atividades não é garantia suficiente do fracasso dessas atividades e, sim, de que, para aqueles que saíram, o PEC não representava o que mais lhes interessava.

Portanto, neste estudo, ao darmos voz aos jovens que se evadiram do PEC e aos que nele permanecem, temos consciência de que a análise dessas vozes não é suficiente, por si só, para identificarmos seus motivos para ação e, assim, exclusivamente a partir dessas falas, para reorientar as estratégias de intervenção do programa.

A orientação pedagógica do PEC, centrada nos objetivos de recontextualizar o espaço para favorecer o desenvolvimento de cidadãos críticos e criativos, reflexivos e autônomos, atribui à comunicação um papel decisivo nos processos de aprendizagem. Essa orientação pesou na decisão em ouvir os remanescentes e os evadidos. 
Enquanto a equipe estava envolvida nos processos de implantação de rotinas e estratégias de gerenciamento das atividades, os jovens se evadiam numa proporção que se revelou preocupante, quando de uma avaliação institucional do projeto, no curso de quatro anos. A partir da análise das fichas de matrícula do Projeto Esporte Cidadão, no período de 2002 a 2005, foi possível constatar que a média de retenção de participantes de um ano para o outro era de 9,4\%, o que significa que $90,6 \%$ abandonavam o projeto no curso de um ano.

Cabia, pois, ouvir os interessados no projeto que nele permaneciam e averiguar, na análise de suas vozes, o que podia continuar, o que precisava mudar e o que tinha de ser mudado imediatamente. Por outro lado, chegou-se à conclusão de que também fazia sentido ouvir os que tinham frequentado o PEC e, no momento, estavam em outras instituições de iniciação físico-desportiva ou por outras razões não mais permaneciam no projeto.

Temos consciência de que, se um problema central é o entendimento dos significados de tamanha "saída", cabe também assinalar que não é certo confiar piamente nos pareceres dos alunos como sentença final para mudar ou continuar as políticas, pois, pressionados a falar, eles produziram os discursos que lhes competiam, que lhes eram convenientes, mas isso não garante que suas respostas devem ser tomadas ao "pé da letra". É nesse sentido que acolhemos a Análise Crítica do Discurso (FAIRCLOUGH, 2003; WODAK; MEYER, 2001; VAN DIJK, 2000) para analisar as respostas dos informantes.

O interesse da Análise Crítica do Discurso (ACD) recai sobre os discursos relacionados com a representação de eventos, na construção de relações sociais, na estruturação, reafirmação e contestação de hegemonias no discurso. $\mathrm{O}$ analista focaliza 
a relação dialética entre discurso e sociedade e busca também desvelar as ideologias que se manifestam implicitamente nos discursos em favor daqueles que se encontram em desvantagem nas relações de poder. No caso deste estudo, a ACD procura explicitar a oposição entre o discurso protagonista (proposta pedagógica implantada pelos coordenadores do PEC) e o discurso antagonista (representações dos participantes acerca das atividades físicas e esportivas), a fim de dar visibilidade aos discursos destes últimos na relação assimétrica de poder que estabelecem entre si.

Entendemos que, ao mesmo tempo em que os indivíduos possuem disposições singulares para as ações que praticam, também constroem representações compartilhadas para justificar e legitimar essas ações. Percebemos a presença do "outro", principalmente nos motivos da evasão e nas representações acerca das competições esportivas, em que os entrevistados internalizam discursos legitimados socialmente para justificar as suas ações, conforme mostraremos mais adiante.

\section{Características sociodemográficas dos entrevistados}

A amostra desta análise se compõe de 83 informantes, 69 evadidos e 14 participantes do PEC. Os informantes concederam entrevistas semiestruturadas, em interação face a face, que foram gravadas e transcritas para serem submetidas à Análise Crítica do Discurso.

Os evadidos, 35 mulheres e 34 homens, permaneceram no projeto por um período médio de 2,3 anos. Foram, portanto, selecionados participantes que abandonaram o projeto tendo experiência considerável sobre ele. Propositadamente, deixamos de entrevistar os que abandonaram o projeto com semanas ou meses de participação. 
O nível de escolaridade do grupo de evadidos varia da sexta série do ensino fundamental ao primeiro ano do ensino médio. Quatro entrevistados possuem defasagem escolar de um a dois anos. Todos os evadidos moram em bairros vizinhos à escola onde o projeto é desenvolvido, que são bairros de baixo nível socioeconômico.

Os perseverantes, sete homens e sete mulheres, têm idade média de 13,5 anos e o tempo médio de permanência no projeto é de 2,2 anos. A escolaridade desse grupo varia da quarta série do ensino fundamental ao terceiro ano do ensino médio. Quatro alunos apresentam defasagem de um ano na relação idade/série.

\section{Motivos da evasão}

Os motivos de evasão foram analisados a partir de dados provenientes de entrevistas com 69 egressos. Os motivos de evasão dos sujeitos entrevistados somam sete, porém grande parte concentra-se apenas em dois motivos: dos 69 evadidos entrevistados, $40 \%$ alegam que deixaram o projeto devido aos estudos, enquanto $30 \%$ dizem que abandonaram o projeto por falta de interesse. Os $30 \%$ restantes afirmam que abandonaram o PEC por questões pessoais, por problemas de doença, por problemas familiares, por mudança de residência e por necessidade de trabalhar.

Essa primeira parte dos dados permite compreender os motivos de desistência da maioria dos evadidos. Os estudos aparecem na fala dos entrevistados como principal fator de evasão. Se observarmos a faixa etária dos entrevistados, constataremos que mais de $60 \%$ dos sujeitos dos dois grupos se encontram entre 13 e 14 anos, idade que, no Brasil, coincide com a transição do ensino fundamental para o ensino médio. A pressão dos estudos nesse nível de ensino é maior do que no nível anterior, o que leva muitos jovens a abandonar a prática sistemática de atividades físicas, conforme 
ilustramos na seguinte fala de um entrevistado, ao responder por que saiu: "Terminei a $8^{a}$ série e onde eu estudo o horário não bate".

No fundo, o projeto é reforçador da escolaridade, pois, para estar no PEC, é preciso estar matriculado na escola. Assim, o jovem é excluído da escola por razões diversas e é excluído dos projetos sociais de lazer por não estar na escola. Além disso, uma parcela considerável se exclui do projeto para estar na escola e no trabalho.

Quando relacionamos gênero com compromissos, verificamos que os depoimentos dos meninos diferem de forma expressiva do que dizem as meninas. Com efeito, os meninos da amostra, além dos estudos, apontam a necessidade de trabalhar desde muito cedo. Mesmo aqueles que só estudam priorizam uma carreira profissionalizante, que lhes garanta uma rápida inserção no mercado de trabalho, como o ingresso em escolas técnicas. As falas de dois meninos evidenciam essa necessidade. O primeiro, por trabalhar e estudar: "Trabalho durante o dia e estudo à noite". O segundo, por ter que se concentrar nos estudos profissionalizantes: "Parei porque estou fazendo escola técnica".

Cada informante apresenta um motivo particular para a desistência do projeto, como incompatibilidade das atividades do PEC com a grade escolar, necessidade de trabalhar e investimento na carreira profissionalizante. Contudo todos os motivos particulares apresentam o estudo como "pano de fundo". Entendemos que os evadidos que justificam o abandono do projeto por causa do estudo utilizam uma convincente estratégia da argumentação (ROJO, 2005), apresentando explicações morais não contestáveis. Se analisarmos a frequência semanal das aulas do projeto (duas aulas de 50 minutos) e a amplitude do quadro de horários, que permite flexibilidade nas opções, percebemos que a "desculpa do estudo" não se sustenta. Também há de se considerar 
que a prática de atividades esportivas pode até favorecer quem se encontra em um processo intenso de estudo, pois alivia o estresse e as tensões. Entendemos por que boa parte dos entrevistados evita tocar em pontos polêmicos, considerando que o interlocutor na entrevista foi um professor da universidade que gerencia o projeto. Eles fazem o discurso politicamente correto e atribuem a evasão a motivos de ordem moral, difíceis ou mesmo impossíveis de serem contestados.

Além dos compromissos de várias ordens e da falta de interesse, a incompatibilidade com a prática de outra atividade esportiva aparece como relevante fator para a desistência das atividades do PEC. Embora diferentes, os dois motivos possuem estreita correlação, pois a proposta pedagógica empregada no projeto, de caráter crítico-superador, tinha como meta principal à formação do cidadão ativo e crítico.

Constatamos que essa proposta tem se mostrado desestimulante para grande parte dos participantes, ao darmos crédito a suas falas. $\mathrm{O}$ fato de o projeto não valorizar a participação em competições esportivas, segundo os informantes, resultaria em aulas monótonas e repetitivas, sem um desafio que excitasse a maioria dos alunos a continuarem no projeto, quer por falta de motivação: "Saí porque os exercícios ficaram repetitivos e não tinha motivação", quer pela ausência de competição: "Não quis mais [...] a gente não disputava nada". Poderíamos dizer que a justificativa se aplica aos muitos motivados pela prática competitiva ou pelos que têm um horizonte de profissionalização, porém não podemos supor que existe a tabula rasa e que todos os atores têm os mesmos motivos com as mesmas intensidades. De fato, o PEC negligenciou a competição esportiva em diferentes dimensões, pois até os menos propensos às competições, quando superada a fase de aprendizagem, sentem-se 
desestimulados, quando não há novos desafios. Daí concluirmos que eliminar a competição do esporte é tirar alguma coisa de sua "essência" (STIGGER; LOVISOLO, 2009).

É difícil garantir que o interesse dos jovens de ambos os sexos se concentra em atividades fora do projeto, em outros projetos, escolinhas ou clubes, que valorizam a participação em competições esportivas. Porém, se observarmos os evadidos, veremos que a maioria permaneceu no projeto por um tempo razoável - mais de dois anos. Aprenderam o que tinham que aprender, usufruíram o que tinham que usufruir e, quando não acharam mais graça, saíram. Isso não significa que o projeto não tenha dado certo. Pensamos que os projetos não são espaços para alojamento permanece. Quando o interesse acabou, os jovens se foram em busca de novos horizontes. Entretanto é incontestável que o projeto não ofereceu condições de continuidade na carreira esportiva, pois seu objetivo limita-se à iniciação esportiva. Estimulados com as possibilidades de competições, eles abandonam o projeto de orientação socioeducativa para investir naquilo que consideram excitante. As competições esportivas, como atividades não entediantes, motivam os jovens, liberam-lhes a adrenalina e são desafiadoras. Tais atividades substituiriam a emoção encontrada na rua, que é perigosa e atraente.

A opção por atividades que valorizam competições esportivas, segundo os depoimentos dos informantes, mostra que o projeto não satisfazia as motivações dos competidores: "Saí porque eu ia apresentar a ginástica rítmica [...] que eu fui para o estadual, aí não deu para ficar mais".

A aluna praticava ginástica rítmica fora do PEC, onde não existe essa atividade. O treinamento e a participação em competições esportivas - campeonato estadual - se 
tornaram incompatíveis com a prática de atividades no projeto, o que levou a aluna a sair dele.

Problemas familiares também favoreciam o abandono do projeto, apesar do pequeno número de recorrência, abaixo de $10 \%$ do total de entrevistados. Na maioria dos casos, os problemas se associam especificamente ao gênero feminino. Com efeito, as jovens sofrem mais cobranças do que os rapazes em relação às atividades domésticas com a família. Algumas participantes justificam a saída, com razões inquestionáveis, que estão acima de qualquer suspeita. Dizem, por exemplo, que foram obrigadas a abandonar o projeto em função das demandas do lar, como revela a fala de uma exparticipante: "Eu saí devido à família [...] tive que ter mais responsabilidade em minha casa, tive que fazer almoço e não tava dando mais para participar do Esporte Cidadão”.

Ginástica rítmica compreendia apenas duas aulas semanais de 50 minutos. Além disso, a modalidade de que a entrevistada participava - dança - só era oferecida no horário das 10h40min às 11h30min, justamente no período próximo ao almoço.

\section{Motivos de adesão}

Identificamos os motivos de adesão ao projeto a partir da análise de todas as 83 entrevistas, isto é, das 69 realizadas com os evadidos e das 14 com os remanescentes. Os dados coletados apontam vários motivos para a adesão, tanto no grupo dos evadidos, quanto no grupo dos que permaneciam no projeto no momento da coleta de dados.

Dos 69 evadidos, 19 afirmaram que entraram no projeto para aprender uma modalidade esportiva, 14 por incentivo de amigos e parentes, 14 para terem o que fazer, oito por motivos de saúde, sete porque possuem afinidade com a modalidade escolhida, quatro para fazer amizades e três por questões estéticas. 
Dos 14 remanescentes, nove disseram que ingressaram porque pretendiam aprender e se desenvolver em uma modalidade esportiva, dois para terem o que fazer, um por motivo de saúde, um para sair da rua e um devido ao incentivo de familiares.

Quando comparamos os motivos para a adesão do grupo de evadidos com os do grupo de participantes, sobressai uma dispersão no grupo dos evadidos e uma concentração no grupo dos participantes. O motivo de adesão com maior índice no grupo de evadidos foi "aprender uma modalidade", que corresponde a $25 \%$ dos motivos de adesão desse grupo. Entre os 14 participantes, 60\% aderiram ao projeto pelo mesmo motivo de aprender uma modalidade esportiva, o que não significa, necessariamente, participar de competições esportivas. Por outro lado, competir é uma etapa posterior ao aprendizado de uma habilidade esportiva.

Enquanto os jovens estão na fase da aprendizagem, não há pressão para competirem. A competição é interna, é deles, com os próprios colegas. Depois que as habilidades são automatizadas, o foco passa a ser externo. Eles começam a competir com os outros. É nesse momento que o projeto tem fraquejado com os que querem competir. Os números sugerem que o grupo de remanescentes possui um foco mais objetivo e realista daquilo que o projeto pode oferecer, enquanto no grupo dos evadidos os motivos para a adesão não estão diretamente associados a uma possibilidade concreta de realização, são menos pragmáticos e são vagos, como indica a fala de um participante: "Eu entrei porque eu não queria ficar parado em casa, ficava no computador, aí eu não gostava disso, enjoei, aí, para não ficar o dia todo sem fazer nada, entrei nesse negócio".

O projeto não deixou de atender a esse objetivo. Mas não atendeu a todos na mesma proporção, pois os objetivos são móveis, vão se reatualizando e vão surgindo 
novos objetivos, na medida em que os anteriores são alcançados. Importa destacar que o motivo forte, aprendizado de uma habilidade esportiva, pode levar a uma permanência maior, se houver esperanças de atingir os demais objetivos; entretanto, mais cedo ou mais tarde, o modo de operar do projeto cai em contradição com a expectativa dos participantes.

\section{A competição esportiva}

A fim de compreender o papel atribuído às competições esportivas pelos evadidos e pelos participantes, efetuamos as seguintes perguntas: você já participou de alguma competição esportiva pelo PEC? Você acha que o PEC deveria valorizar a participação em competições esportivas? Por quê?

Dos 69 evadidos, 33 participaram de competições esportivas contra 36 que não competem. Dos 14 participantes, dez já participaram e quatro não. Todos os entrevistados, mesmo os que nunca participaram, ressaltaram a importância das competições esportivas.

No grupo dos evadidos, 22 entrevistados vêem as competições esportivas como forma de desenvolver o aprendizado da modalidade. Consideram o momento da competição oportuno para validar a técnica adquirida: "Porque vai ensinar a pessoa a nadar, pessoas que nunca participaram de competições para ir desenvolvendo o nado".

Dezoito evadidos consideram as competições muito importantes para seu desenvolvimento na modalidade. A competição serve como teste para verificar a aptidão adquirida e os limites individuais: "É bom para ver a capacidade de cada um". 
Também os 18 evadidos ressaltaram o papel da competição como fator motivacional. O desafio os leva a continuar no projeto: "É bom, os alunos têm uma motivação a mais para participar do projeto".

Onze evadidos vêem a competição como meio de ascensão na carreira esportiva. A competição garante a visibilidade necessária para que os talentos individuais sejam detectados. Ela dá acesso a contextos esportivos mais estruturados: "Pode vir pessoas de fora, ver que aquela pessoa é boa, aí pode chamar para competir em outros lugares, aí a pessoa vai ficando importante $[\ldots]$ "..

A possibilidade de competir em outros lugares e a motivação são os fatores que os participantes mais valorizam para priorizar a competição esportiva. Os participantes ressaltam a competição esportiva como possibilidade de trânsito em outros contextos. Nos termos de Vianna (2007, p. 189): "Questionamos se a vivência no esporte pode estar contribuindo para que esses sujeitos ultrapassem a perspectiva determinista de limitação da posição social para além da sua herança cultural”.

A competição esportiva é uma forma de alcançar mobilidade social e regional: "Competir melhor, em outros lugares, por exemplo, sair daqui para outro lugar". Um grupo de quatro participantes também vê a competição como elemento de motivação para a prática. A competição mantém o interesse pela modalidade esportiva. Alguns participantes ressaltam a competição como fator crítico para manter o interesse dos alunos no projeto: “[...] se a gente não tiver competições, a gente só vai ficar treinando, treinando [...] aí a gente vai se desinteressar”. Eles dão um belo testemunho de voz, com ameaça de saída, no sentido de Hirschman (1973): “[...] se não tiver nada para fazer no final do ano, a gente não vai querer fazer mais". 
Na perspectiva da Análise Crítica do Discurso, pode-se afirmar que parte dos discursos dos entrevistados possui significado identificacional, pois estão relacionados com a construção da identidade dos sujeitos. Esses discursos são marcados por afirmações avaliativas, que utilizam expressões circunstanciais, como "competir melhor", e com verbos de processos mentais afetivos, como "eu não gostava disso". O significado identificacional presente nos discursos revela o grau de comprometimento dos falantes com aquilo que dizem. Esse comprometimento dos entrevistados está associado ao aprendizado e à prática das modalidades esportivas. A perspectiva identificacional dos entrevistados é conflitante com a proposta pedagógica do projeto, em que a ênfase das intervenções recai sobre o significado representacional. Com efeito, entre os objetivos iniciais do PEC, destacava-se o de construir representações críticas acerca das atividades físicas e esportivas, capazes de instrumentalizar os participantes para o processo de transformação social.

A ACD também permite verificar que parte dos discursos que defendem a participação em competições esportivas não possui marcas identificacionais. Trata-se de enunciados construídos pelo discurso indireto, por meio de proposições objetivas, em que o autor não explicita a base subjetiva do seu comprometimento. Há uma universalização da perspectiva defendida, uma vez que não aparecem marcas particulares no discurso, que é "tomado tacitamente como verdadeiro". Parte significativa dos discursos que defendem a competição esportiva não traz marcas pessoais, são afirmações em que os autores não estão implicados diretamente naquilo que dizem, por exemplo: “[...] os alunos têm uma motivação [...]" ou “[...] ver que aquela pessoa é boa [...]". Nos exemplos citados, observa-se que, em vez do pronome “eu”, aparecem os nomes "alunos" ou "pessoa". 
Consideramos que a ausência do discurso direto decorre da falta de experiência de parte dos participantes com as competições esportivas. As representações não foram construídas com base na experiência empírica. Por essa razão, parte dos entrevistados reproduziu em seus discursos representações que circulam nos meios de comunicação de massa, que enfatizam o lado positivo das competições esportivas.

\section{Considerações Finais}

As representações de evadidos e perseverantes do Projeto Esporte Cidadão sobre os motivos de evasão e de adesão e sobre o papel da competição esportiva indicam que há conflito entre a proposta pedagógica adotada pelo PEC e os sentidos que os sujeitos constroem para sua ação. Apesar dos fatores externos que contribuem para a evasão, como os estudos e os problemas familiares, os discursos e as práticas dos entrevistados revelam que suas motivações para a prática de atividades físicas e esportivas não coincidem com os valores defendidos pela proposta socioeducativa.

No contexto do projeto investigado, percebemos que os participantes experimentaram, aceitaram por tempo limitado ou mesmo rejeitaram a proposta a que estavam submetidos. A saída e a voz se constituíram em importantes mecanismos para verificação do nível de adesão e retenção ao projeto investigado, fornecendo meios para constatação do nível de satisfação dos participantes com o programa. O projeto falhou ao não priorizar a aquisição das habilidades técnicas relativas às diferentes modalidades esportivas e negligenciar as competições esportivas.

Em vista das constatações acima, os responsáveis pelo projeto implementaram mudanças de prioridade nas ações pedagógicas e nas oportunidades de competição interna e externa, com resultados animadores, em termos de mudança da voz e, 
sobretudo, de permanência no projeto. Os números apontam para um novo equilíbrio, com um quarto de retenção contra menos de dez por cento quando se seguia a proposta original.

\section{Referências}

ELIAS, N.; DUNNING, E. Memória e sociedade: a busca da excitação. Lisboa: Difel, 1992.

FAIRCLOUGH, N. Analysing discourse: textual analysis for social research. London; New York: Routledge, 2003.

HIRSCHMAN, A. Saída, voz e lealdade: reações ao declínio de firmas, organizações e estados. São Paulo: Perspectiva, 1973.

LOVISOLO, H. R. Da educação física escolar: intelecto, emoção e corpo. São Paulo, Motriz, v. 8, n. 3, p. 15-18, 2002.

Mediação: esporte rendimento e esporte na escola. Porto Alegre, Revista Movimento, v. 7, n.15, p. 107-116, 2001.

Normas, utilidades e gosto na aprendizagem. In: VOTRE, S. J.; COSTA, V. L. M. (Org.). Cultura, atividade corporal e esporte. Rio de Janeiro: Editora da UGF, 1995.

ROJO, L. M. A fronteira interior: análise crítica do discurso: um exemplo sobre racismo. In: IÑIGUEZ, L. Manual de análise do discurso em ciências sociais. 2. ed. Petrópolis: Vozes, 2005.

SOARES, C. L. et al. Metodologia do ensino de educação física. São Paulo: Cortez, 1992.

STIGGER, M. P.; LOVISOLO, H. (Org.). Esporte de rendimento e esporte na escola. Campinas: Autores Associados, 2009.

VAN DIJK, T. A. (Org.). El discurso como interacción social. Barcelona: Editorial Gedisa, 2000.

VIANNA, J. A. Esporte e camadas populares: inclusão e profissionalização. 2007. 238 f. Tese (Doutorado em Educação Física) - Universidade Gama Filho, Rio de Janeiro, 2007.

WODAK, R.; MEYER, M. (Org.). Methods of critical discourse analysis. London; Thousand Oaks; New Delhi: Sage Publications, 2001. 
André da S. Mello, Sebastião J. Votre e

\section{Endereço dos Autores:}

André da Silva Mello

Rua Joaquim Lírio, 220/602 - Praia do Canto

Cep: 29055-460 - Vitória - ES

Endereço Eletrônico: andremellovix@gmail.com 